\title{
Eligibility Waiver
}

National Cancer Institute

\section{Source}

National Cancer Institute. Eligibility Waiver. NCI Thesaurus. Code C42580.

An approved exemption to the requirement for a participant to meet eligibility criteria

prior to study enrollment. A sponsor-approved waiver is necessary when a subject fails to meet enrollment criteria, but wishes to be accrued to the trial. 